\title{
Frontiers
}

\section{in the Psychotherapy} of Trauma \& Dissociation

The Official Clinical Journal of the International Society for the Study of Trauma and Dissociation

Flash Technique for Safe Desensitization of Memories and Fusion of Parts in DID: Modifications and Resourcing Strategies

Neva Shebini, MBBS BSc (Hons) MRCPsych FRANZCP 


\title{
Frontiers in the Psychotherapy of Trauma \& Dissociation
}

The Official Clinical Journal of the ISSTD

\section{EDITOR}

ANDREAS LADDIS, MD, Private Practice and Faculty, Boston University, School of Public Health, Boston, Massachusetts, USA

\author{
ASSOCIATE EDITOR \\ MARTIN J DORAHY, PhD, Professor, Department of Psychology, University of Canterbury, \\ Christchurch, New Zealand and The Cannan Institute, Brisbane, Australia
}

\section{EDITORIAL ASSISTANT}

COURTENAY CRUCIL, MA, RCC, Private Practice, Terrace, British Columbia, Canada

\begin{abstract}
Frontiers in the Psychotherapy of Trauma \& Dissociation is published by the International Society for the Study of Trauma and Dissociation, Inc., 1420 New York Ave NW, Fifth Floor, Washington, DC 20005.
\end{abstract}

\section{Annual Subscription, Volume 3, 2019}

Online subscription is part of the membership dues of the International Society for the Study of Trauma and Dissociation. Visit https://www.isst-d.org/join-isstd/individualmember-benefits/.

Production and Advertising Office: ISSTD Headquarters, 1420 New York Ave NW, Fifth Floor, Washington, DC 20005.

Copyright @2019 International Society for the Study of Trauma and Dissociation. All rights reserved. No part of this publication may be reproduced, stored, transmitted, or disseminated in any for or by any means without prior written permission from the International Society for the Study of Trauma and Dissociation. The publisher assumes no responsibility for any statements of fact or opinion expressed in the published papers. The appearance of advertising in this journal does not constitute an endorsement or approval by the publisher, the editor, the editorial board, or the board of directors of the International Society for the Study of Trauma and Dissociation of the quality or value of the product advertised or of the claims made of it by its manufacturer.

Subscriptions to this journal are acquired through membership in the International Society for the Study of Trauma and Dissociation only.

Visit https://www.isst-d.org/join-isstd/individual-memberhip-categories/.

Permissions. For further information, please write to info@isst-d.org.

\section{EDITORIAL BOARD}

ELIZABETH S BOWMAN, MD, Editor Emerita, Journal of Trauma \& Dissociation, Adjunct Professor of Neurology, Indiana University School of Medicine, Indianapolis, Indiana, USA

LAURA S. BROWN, PhD, Private Practice, Seattle, Washington, USA

RICHARD A CHEFETZ, MD, Private Practice, Faculty and Founding Member Institute of Contemporary Psychotherapy \& Psychoanalysis, Distinguished Visiting Lecturer: William Alanson White Institute of Psychiatry, Psychoanalysis \& Psychology, New York City, USA

CONSTANCE J DALENBERG, PhD, Trauma Research Institute, California School of Professional Psychology, San Diego, California, USA

J.K. JUDITH DANIELS, PhD, Faculty of Behavioural and Social Sciences, University of Groningen, The Netherlands

STEVEN N GOLD, PhD, Professor, Center for Psychological Studies, and Founding Director, Trauma Resolution \& Integration Program, Nova Southeastern University, Fort Lauderdale, Florida, USA ELIZABETH B HEGEMAN, PhD, Professor, Department of Anthropology, John Jay College of Criminal Justice, New York, New York, USA 
RICHARD P. KLUFT, MD, PhD Private Practice and Clinical Professor of Psychiatry, Temple University School of Medicine; Faculty Member, Philadelphia Center for Psychoanalysis,

Philadelphia, Pennsylvania, USA

CHRISTA KRÜGER, MD, Professor of Psychiatry, University of Pretoria, Pretoria, Gauteng, South Africa

KARLEN LYONS-RUTH, PhD, Professor of Psychology, Harvard Medical School, Cambridge, Massachusetts, USA

ALFONSO MARTÍNEZ-TABOAS, PhD, Professor, Albizu University, San Juan, Puerto Rico WARWICK MIDDLETON, MD, Adjunct Professor, Cannan Institute, Brisbane, Australia

ELLERT R. S. NIJENHUIS, PhD, Department of Psychiatry and Outpatient Department Mental Health Care Drenthe, Assen, The Netherlands

SANDRA PAULSEN, PhD, Bainbridge Institute for Integrative Psychology, Bainbridge Island, Washington, USA

VEDAT SAR, MD, Professor of Psychiatry, Koç University School of Medicine (KUSOM), Istanbul, Turkey

JOYANNA SILBERG, PhD, Trauma Disorders Program, Sheppard Pratt Health Systems, Baltimore, Maryland, USA

ELI SOMER, PhD, Professor, School of Social Work, University of Haifa, Israel

KATHY STEELE, MN, CS, Private Practice, Atlanta, Georgia, USA

ONNO VAN DER HART, PhD Emeritus Professor of Psychopathology of Chronic Traumatization, Department of Clinical and Health Psychology, Utrecht University, Utrecht, The Netherlands VICTOR WELZANT, PsyD, Sheppard Pratt Health Systems, Trauma Disorders Program

\section{REVIEWERS}

JOHN BRIERE, PhD, Associate Professor of Psychiatry and Psychology, University of Southern California Keck School of Medicine, Los Angeles, California, USA

SHELDON IZKOWITZ, PhD, Clinical Associate Professor of Psychology and Clinical Consultant, Postdoctoral Program, New York University, New York City, USA and Teaching Faculty \& Supervisor of Psychotherapy and Psychoanalysis, National Institute for Psychotherapies, New York City, USA

MARY-ANNE KATE, PhD Researcher at University of New England, Australia; University of New England, New South Wales, Australia

ULRICH F. LANIUS, PhD, Private Practice, West Vancouver, British Columbia, Canada

\section{SUPPORTERS}

ISSTD thanks its generous supporters whose contributions have made this publication possible:

Andreas Laddis, MD, USA

\section{The \\ Cannan \\ Institute}

Cannan Institute, Australia

Warwick Middleton, MD, Australia

Dana Ross, MD, Canada

Martin J. Dorahy, PhD, New Zealand

Kate McMaugh, Australia

Sara Y. Krakauer, USA

Paula Eagle, MD, USA 


\title{
ARTICLE
}

\section{FLASH TECHNIQUE FOR SAFE DESENSITIZATION OF MEMORIES AND FUSION OF PARTS IN DID: MODIFICATIONS AND RESOURCING STRATEGIES}

\author{
NEVA SHEBINI, MBBS BSc (Hons) MRCPsych FRANZCP \\ Consultant Psychiatrist
}

This paper explores the use of the Flash technique in the treatment of extreme trauma in Dissociative Identity Disorder (DID) from satanic ritual abuse. The results include desensitization of trauma memories and the planned fusion of parts. I share my insights on safe application of the technique and modifications that can be used for highly fragmented DID clients and other complex trauma presentations. Strategies include ways to safely assess the severity of the memory, modifications in the Subjective Units of Distress (SUDS) measurement, instructions in applying the technique, modes of bilateral stimulation and use of the conference room technique. Nine case sessions are documented demonstrating nine variations in use of the technique. I describe how to install an engaging activity in parts that cannot come up with a resource. Additionally, I write about the use of playful extra resourcing to strengthen the engaging activity, leading to "boosting" of the Flash therapy session and hence faster processing of trauma memories. I hope that colleagues working in the field of trauma and dissociation can find the tools and strategies in this paper helpful for their professional development and also for treatment of their clients.

Acknowledgements: Thank you to Bessel Van der Kolk for his support and wisdom and encouraging me to write this up. Thank you to Graham Taylor who taught me the Flash technique and thanks to my client who has made this possible.

Author Contact Information - Private Practice, Peace of Mind Services Ltd., Cairns, Queensland, Australia, Tel. +61 0740310419, email: Info@peaceofmindservices.com.au. 
KEYWORDS Flash technique; dissociative identity disorder; satanic ritual abuse; conference room; EMDR; fusion of parts; Flash technique boosting; resourcing; play; psychotherapy

This is the second part in a series of two papers on the subject of trauma memory desensitization and fusion of parts in a case of extreme DID from satanic ritual abuse. The first paper focused on the use of EMDR (Shebini, 2019). This paper focuses on the application of the Flash technique to facilitate trauma memory processing (Manfield, Lovett, Engel, \& Manfield, 2017).

\section{BACKGROUND OF PATIENT}

For six years, I have been working with a highly fragmented client with an extremely complex system, who reported severe abuse in a satanic cult over many years. She has a diagnosis of DID with approximately 300 child parts of self, making her a more extreme case of DID. Many of these younger parts have up to 20 traumatic memory fragments each. She has approximately seven older parts who have experienced many more trauma events. I estimated that my client had approximately 1,000 trauma memories, divided amongst parts. Once adequate stability in phase 1 was established, phase 2 trauma therapy could begin. As I described in my first paper (Shebini, 2019), I delivered Eye Movement Desensitization and Reprocessing (EMDR) therapy (Shapiro, 1995) with modifications for DID; the outcome was integration of approximately 100 parts within the personality system in a 12-month period. I later used the Flash technique (Manfield et al., 2017) as a desensitization tool for extreme trauma memories.

\section{THE FLASH TECHNIQUE}

This tool is a simple, yet effective method that uses micro-exposure to reduce the "intensity" of severe trauma memories (Manfield el al., 2017). It can be used before EMDR in the preparation phase (Shapiro, 1995). A rough guide is that it can be used if the SUDS is high, at a level of 8 or above out of 10. Significant desensitization can take as little as a few minutes. However, I found that some sessions could take up to 45 minutes for one DID part.

The intensity of the trauma memory is rated with a SUDS at the start of the session. The client is then advised to get into a neutral or resourced state; the latter is something that gives the client a feeling of calmness or wellbeing. Then slow bilateral stimulation (BLS) is applied, whilst guiding 
the client to alter their blinking. The recommended rate of BLS is 2-3 seconds per each eye movement pass (left-right-left), and a full Flash set is usually $4-5$ passes. They will need several sets to reduce the intensity of the memory. The therapist says, "Flash" at intervals during the BLS, to indicate that it is time to quickly blink three times.

The client quickly reviews the memory and how it has changed between each Flash set. This process is repeated until the memory is more manageable for them and EMDR can then be used to further process the memory. The memory can also be diminished to the point where the client may not even need EMDR (see case examples below).

\section{TIPS FOR FLASH THERAPY}

\section{Stabilization}

The host personality (main part presenting for treatment) and at least some of the parts must be comfortable with using affect regulation and distress tolerance techniques before engaging in the Flash technique. I recommend the presence of an older, experienced internal self-helper (part $\mathrm{W}$ in this client) to be present during the therapy, to assist the younger parts if needed (Paulsen, 2009).

\section{Memory Review}

When I ask parts to "review" their memory before applying the Flash technique, I need to ensure that they do not become flooded or "stuck" in the memory. Risks can include re-living the trauma, fear, dissociation, loss of rapport and an unstable client who will need stabilization before they leave the session. In the treatment of DID, parts often use containment strategies for their memories, for example, an imagined secured box or container. Parts can choose to quickly peek "inside" the lid of the box, or just look briefly "at" the box from the outside. If their memory is not in a container, I advise them to briefly look at the memory from "far away." This brief "look" may take just one or two seconds, if not less. The therapist can then get a measure of how distressing their memory is, before the treatment begins.

\section{Subjective Units of Distress (SUDS)}

If a part can use the concept of SUDS, then this measure is used. However, I have often found that younger parts cannot conceptualize the idea of numbers on a scale from " 1 to 10 " and how "bad" they feel on it. In these situations, I believe it is not essential to obtain a number for the SUDS. Alternative ways to get an idea of their distress levels can be with words (for example, "really yucky"), with hand signals (higher indicates more 
distress), pointing to where they feel the distress in their body and using picture charts showing different emotions. One should remember that at the beginning of the session, their memory is likely to be very disturbing, so if they struggle to describe the severity, I suggest avoiding dwelling on this and commence Flash therapy as soon as possible. After a few sets of Flash therapy, the memory should reduce in intensity, so the part will eventually be able to convey the reductions in intensity.

\section{Bilateral Stimulation (BLS)}

My clients and I prefer using bilateral stimulators, for several reasons. I can maintain full observation of the client whilst the stimulators are on, with less concentration on the need to get the finger movements at the "right" level, speed and angle. Their eyes do not get tired, as they do not need to follow a moving finger. Many clients also find the feel of the buzzers in their hands to be calming. The client has more control over the BLS as they can adjust the speed and intensity on the device controller. And my favorite thing is that clients can close their eyes (if they wish) and focus on the experience.

\section{"Flash"}

When instructing the parts to blink in the pre-taught way, one says "flash" and they blink three times. I opted to change the word "flash" to a more neutral word "blink." The word "flash" can be linked to sexual abuse. It can be associated with child pornography, when cameras took photos and "flashed," as was the case with my client. I believe it is up to the therapist to decide if the word "flash" will be a neutral stimulus or a trigger for their clients. If they wish to close their eyes during Flash therapy, when instructed to "blink," they can open their eyes and blink three times, then close them again.

\section{Conference Room Technique}

I believe the conference room technique (Fraser, 1991) is essential for this kind of trauma work with DID, where risks of destabilization from flooding are high. Parts within the conference room can safely have trauma therapy without exposing other parts in the system. One part will be at the "front" of the conference room, present on the "outside" in the therapy office with the therapist and experiencing the external BLS. The parts on the inside feel and experience the BLS at the same time as the external part. All parts in the session can see and hear the therapist; they blink simultaneously, in their Flash therapy session. 


\section{VARIATIONS IN THE FLASH TECHNIQUE}

Below are nine case session examples exploring variations in the use of the Flash technique in DID. The first five examples involve the desensitization of one memory; the final two involve multiple memory desensitization.

\section{SESSION 1: TWO OUT OF FOUR PARTS HAVE FLASH THERAPY}

A trauma memory was selected which involved four child parts. For this memory, I was informed (by helper part W) that two of the parts (part 2 and part 4) had more "severe" experiences from that trauma event, compared to parts 1 and 3 . Their body memories were very distressing with intense pain. As such, the Flash technique was trialed with just part 2 and then with part 4 . The aim was to lessen the intensity of their memories, with the hope to then use EMDR with all four parts together.

Part 2 had Flash therapy first. During the session, part 2 was present in the therapy office with me, and helper part $\mathrm{W}$ was co-conscious, observing from inside the conference room. The three younger parts waited in the conference room waiting room, where they could not hear or see the therapy, to minimize flooding. After approximately just 10 minutes of Flash therapy, part 2's memory became less intense with minimal somatic experiences remaining. Then part 2 moved into the waiting room whilst the Flash technique was used with part 4 , until her memory also became less intense. Both parts' SUDS dropped from 10/10 to 3/10, and they each needed five Flash sets. This process took about 20 minutes for both parts 2 and 4 . This was a successful outcome for parts 2 and 4 .

All four parts were then brought back into the conference room where they had co-consciousness with one another. The plan was to deliver EMDR for the four parts. Part $\mathrm{W}$ was at the front of the conference room and present in the therapy office with me, holding the bilateral stimulators in each hand. EMDR desensitization commenced, with part 1's memory first, then to part 2, then part 3 and then part 4 (i.e., sequential dissociation, as described in Van der Hart, Steele, Boon, \& Brown, 1993). The difference in processing was immediately noticeable and of significance. For the first round of EMDR, parts that had the Flash therapy played their memories through rapidly, with minimal distress. It was as if parts 2 and 4 were on their third "pass" or "re-play" of their memory with EMDR. However, the parts that did not have Flash therapy processed more slowly, at the "normal" EMDR pace, with higher levels of emotional and somatic distress. Part 1 even complained to me as she could "see" the difference in speed and intensity and said, "How come theirs is faster than mine?"

It was evident that the Flash technique successfully reduced the intensity of the targeted memories, as demonstrated in this EMDR session. 


\section{SESSION 2: FOUR PARTS HAVE SIMULTANEOUS FLASH THERAPY}

Another trauma memory with the involvement of four parts was selected and used as the target for the session. The conference room was set up, and the four parts were inside; helper part $\mathrm{W}$ was present on the outside, in the therapy office with me. The Flash technique was then trialed in a slightly different way, which I hypothesized to be potentially easier and quicker.

These parts were able to give a SUDS reading; part A rated 5/10, part $B$ rated $6 / 10$, part $C$ rated $7 / 10$ and part $D$ was at $8 / 10$. The four parts were simultaneously guided to imagine engaging in something pleasant (patting a pet), and part $W$ was holding the bilateral stimulators in each hand. Slow BLS was delivered, and they were instructed to blink, as per the Flash protocol. I checked their individual memory fragments in between Flash sets, and then the process was repeated. Each time I checked their memories, all four parts had some reduction in intensity to differing degrees. After several further sets of Flash therapy, all four parts' memories became diminished, each with SUDS of $0 / 10$. This was another successful outcome and a great result.

\section{SESSION 3: PLANNED FUSION}

Continuing with session 2 above, once the intensity of the memories became diminished, it was then opportunity to use EMDR. However, in this particular example, this was part C's "last" remaining memory, so complete desensitization could have led to fusion, within the personality system. Fusion refers to the joining of two or more parts with a complete loss of subjective separateness (International Society for the Study of Trauma \& Dissociation [ISSTD], 2011). I was curious to see if this was possible without EMDR and with Flash therapy.

At that point, instead of using EMDR, the Flash technique was further used for part $\mathrm{C}$ alone, to see if fusion could occur. Reassurance was given to part $C$; she asked questions, including what it would mean to "fuse." After several more sets of Flash therapy, the memory became extremely small for her, and somatic sensations became nil. On the final set of Flash therapy, her eyes gently rolled upwards, and she appeared asleep and peaceful. This appeared to be a Spiegel eye roll (Spiegel, 1972). After around 30 seconds, helper part W came out into the office with me. She confirmed that the part $\mathrm{C}$ had in fact "gone inside" and fused. This was another great result, fusion of a part within the personality system, using the Flash technique. 


\section{Resourced State / Engaging Activity}

Manfield and colleagues (2017) recommend using a "neutral or resourced state." The resourced state can be the imagining of an engaging activity. This may not be as straightforward to conduct as one may assume. There are two key elements of an engaging activity. First, they need to imagine, in the present moment, actually "doing" the engaging activity. Second, they should also be able to feel some positive somatic experiences in the present moment, from the engaging activity. These somatic experiences can be a feeling of calmness or wellbeing. This may be quite manageable in clients without DID, who have had positive experiences in their lives.

But difficulties are likely to arise in a client with DID who has parts that have really never experienced pleasant things in their existence. In fact, they sometimes do not even understand when I suggest to "imagine or pretend doing something you enjoy," or "makes you feel good or happy." Firstly, some parts do not understand the words "imagine" and "pretend"; these may be too technical a concept and not in their limited vocabulary. Words can be changed to more basic terms like "try and picture" or "think about." I have also been questioned about the words "feel good," "happy" and "enjoy" as these are often foreign concepts to them. Most of these parts have only ever known trauma and pain, and they have never experienced positive physiological sensations in their body. So how does one help a part to have an engaging activity and feel positive feelings from it? Without this, I believe Flash therapy is less likely to be as effective. I would like to share three methods that I successfully trialed and used with this client.

The first engaging activity method used is when a part "uses" the host's engaging activity. The host has a favorite pet and can feel positive emotions and somatic sensations when stroking the animal on its head. Some parts enjoyed observing the pet being stroked. Before the sessions, the host worked with some of the parts and let them "come out" at home whilst stroking the pet, to strengthen that somatic component. Those parts could then use this resource during their Flash therapy session. In the first three case sessions documented above, the engaging activity used was imagining patting the house pet.

This method is quite effective, if attention is paid to making it work. However, I had several parts who could not connect with neutral or positive body experiences when stroking the pet, or they were just not interested in the pet. In the case sessions below, alternative engaging activities were used.

\section{SESSION 4: “REAL” ENGAGING ACTIVITIES}

I wondered if I could use an engaging activity that was not "imagined." I worked with a six-year-old part (part D) who had an extensive abuse 
history with torture and inhumane practices with animals; we tried to find any imagined engaging activity. We tried several, and although she could imagine them well, nothing was changing in her body, despite her best attempts. She remained flat and detached. We could not even achieve a resource that felt "neutral" for her. For months prior to her trauma therapy, part D often emerged abruptly during therapy sessions, asking for my help to get rid of the scary, horrible nightmares and "video recordings" in her head. At home, the host and helper parts would teach part D how to breathe, use containment strategies and distraction techniques, including drawing. One thing she liked to do was draw, and she often gave me drawings that she made in between sessions.

The second variation in the engaging activity was trialed in this session. She had her lovely selection of colored pens, stickers and a piece of paper. Clearly, eye movements for BLS would be impossible here, as she was looking down at her paper and drawing. The bilateral stimulators were put into the pockets of her jeans, and she agreed on the setting at the start. Interestingly with the BLS, she was finally able to feel positive sensations in her body, as she busily colored in trees, cats and owls. She liked putting stickers of birds on her drawings. Once we started Flash therapy, it was evident that she felt more and more excitement in her body as she tried to color and draw as much as she could within a 20 second Flash set. This method was a great success, and she was finally able to diminish her trauma memory experience from feeling horrific to neutral, with no remaining subjective or objective distress. This took about 20 Flash sets and 30 minutes.

After this success, part D had further Flash therapy with several more memories successfully "diminished," with drawing and coloring as her engaging activity. This confirms that external and "real" engaging activities can be used as an alternative to imagined resources.

\section{SESSION 5: LET'S TALK ABOUT UNICORNS!}

Part D had some memories of her own but had five memories shared with six-year-old part E, who had been split off and created from part D, during their extreme abuse. I planned to deliver Flash therapy to both of them at the same time. Like many parts, part $E$ struggled to know what an engaging activity was and how to experience positive body sensations. One possibility was to have part $\mathrm{D}$ on the outside in the room with me coloring, and part $\mathrm{E}$ within the conference room, observing. However, part $\mathrm{E}$ was not very interested in part D's coloring, and positive body sensations could not be shared.

I did some individual work with part E. We looked at trying to find anything pleasant that she could relate to. The client had two colorful stuffed unicorns that parts D and $\mathrm{E}$ had assembled individually at home, as a form 
of distraction and grounding. I suggested that she could imagine playing with the unicorn, as a stuffed toy. This did not seem enough so I went a step further and suggested sitting on the unicorn and flying. She closed her eyes and could imagine this.

We persisted with the flying unicorn concept and enhanced this resource by getting her to share with me what she could see, hear, smell, feel and experience. She could see the water down below, feel herself holding the unicorn, feel the breeze on her body and see the colored mane moving in the breeze. She could even smell the unicorn. I playfully and curiously asked, "Oh, what does a unicorn smell like?" She said, "Ah it smells a bit like a horse, but it's a unicorn smell." "Oh wonderful," I said very happily and intrigued. Slow BLS was used with the bilateral stimulators, to enhance her resource, which it did beautifully. Her experiences of flying, the sights, smells and feelings of safety and happiness were all strengthened. We had found, and built in, not only a resource, but also an engaging activity for the Flash technique.

Part D was then brought into the conference room, and we showed her part E's new resource. I asked if she wanted one too. She did. After a little time and similar resource installation in part $\mathrm{D}$, she too had her own unicorn to fly on.

They were finally ready. The third variation for the engaging activity was utilized in this session. Both flew on their unicorns during their Flash therapy. What made this more interesting and lovely to be a part of was hearing how these two parts decided to happily fly on their unicorns together, side by side. This was in contrast to a few weeks prior when these two parts had no intentions of working together. Part E had previously expressed anger and blame towards part D for "allowing" their abuse to happen in the first place. However, they were now able to work together. After each Flash set, I asked them how their trauma memory had changed. I also checked with helper part W (present on the outside with me) about how they were doing with their flying unicorns, as she could "see inside." Part W often chuckled and said, "If only you could just see what they are doing!" She said that the parts were very happy and racing one another in the sky.

Both parts needed just fifteen minutes together until their memories had diminished significantly. This was another great outcome. I believe this was strongly related to the fact that these parts could be playful, have fun and really enjoy their activity. They felt strong positive somatic sensations which allowed the Flash technique to work most effectively.

\section{SESSION 6: “BOOSTING” WITH ADDITIONAL RESOURCES}

Six-year-old parts D and E had several further Flash therapy sessions together. They continued flying on their unicorns and did well in their therapy. During the second flying unicorn session, I playfully handed them a 
toy magic wand (from my office) with shiny colored sequins and glitter that moved up and down inside it. I jokingly said, "I wonder if unicorns farted, if it would look magical like this?" I did not expect this comment to lead to a whole other progression in "boosting" of their memory desensitization.

First of all, helper part W chuckled, and then she told me that the two parts inside were having "belly laughs" at my comment. Part W warmly told me, "They have never had belly laughs before." This was wonderful to hear. Belly laughing would have certainly reduced the physical tension within the body and also enhanced the felt positive somatic sensations with a sense of wellbeing.

I continued the Flash therapy with them, but during that session, I soon found myself laughing out loud at my own thoughts, which I shared with them. I said, "I wonder if I would find anything on the Internet if I searched images for "unicorn farts'!" They all laughed again and were more interested in seeing what I could find online than doing their Flash therapy. Well, what a surprise, over a million "hits" came up in just a fraction of a second. We browsed the comical and beautiful images of unicorns and unicorn farts. For those that are curious, unicorn farts are often depicted as rainbows and shiny magical glitter trails. There is a whole new world out there of random things one can purchase online relating to unicorns and their farts. Amongst these things, we came across an overseas site selling beautiful "unicorn fart candles" which looked like a delightful ice cream sundae with rainbow colors and whipped cream wax on top, covered with sparkles. I knew straight away that I had to order some, and after the session, I did just that.

We stopped browsing the internet and continued Flash therapy with both parts. Interestingly, both then chose to add sparkly glitter fart trails behind their unicorns. As the bilateral stimulators were on, they both imagined the glitter farts propelling the unicorns to fly higher and faster. The parts were again chuckling during the Flash session (reported by part W) as they tried to race one another and see which unicorn could overtake the other. The result was even faster desensitization of that trauma memory in around just 10 minutes. I believe this added extra sensory resource and playful approach allowed "boosting" of their positive experiences and hence accelerated their memory desensitization.

\section{SESSION 7: BOOSTING WITH OLFACTORY RESOURCES}

Two weeks later, the glorious "unicorn fart candle" arrived, and I brought one to the session specifically for work with parts D and E. The candle did not need to be lit; it smelt divine, fruity, sweet and very comforting, and had a magical look and feel to it. The parts loved it and were excited at the new magical tool that we had. 
Parts D and E were situated inside the conference room, and helper part $\mathrm{W}$ was in the therapy office with me (holding the bilateral stimulators in each hand). Parts D and E boarded their unicorns and started to fly again. The candle was next to them (not lit), and part $\mathrm{W}$ looked at this magical sight and inhaled the candle's sweet smell. The parts inside could smell it too, and they loved it. This seemed to further strengthen their sensory resource experience, and they both had full desensitization of their memories in around 9 minutes total. I deduced that adding in this extra olfactory resource in Flash therapy allowed for even faster desensitization of trauma memories, as compared to without this extra resource.

\section{SESSION 8: DESENSITIZATION OF TWO DIFFERENT MEMORIES SIMULTANEOUSLY}

Parts D and E also had individual memories that were not shared, from different trauma events within the cult ceremonies. I wondered if it was possible to process two totally different memories at the same time. This would require substantial mental work from the parts, and I was unsure if it would be a success and if it would cause symptoms such as fatigue, headache and dissociation. The parts were agreeable to trial this method. Success would mean that significant time could be saved in therapy, as two memories could be processed in half the time.

Two separate memories were selected for this therapy session. The engaging activities used were the flying unicorns with propelling glitter trains and the added olfactory resource. Once Flash therapy commenced, helper part $\mathrm{W}$ (present on the outside with me) noticed that the two parts were not flying together anymore, but they were in their own scenery, on "split screens." I suspected this occurred because the memories were not shared; in the examples mentioned above, the parts were flying together in the same scene, likely because they shared the same memory. In my opinion, the "split screen" seemed analogous to a dissociative barrier.

In between the Flash sets, I asked parts D and E (via part W) how their memories were changing. The two separate memories desensitized in a similar way to when one memory was targeted and desensitized. Together, the two parts diminished their individual memories in 10 minutes collectively, which is a similar amount of time for one memory to be processed. This example demonstrates that more than one memory can be targeted and desensitized at the same time and with the same duration as one memory. Trained therapists could potentially utilize this variation method and desensitize memories in a fraction of the time that traditional therapies would take. This was another fantastic finding of use for the Flash technique. 


\section{SESSION 9: DESENSITIZATION OF TWO DIFFERENT MEMORIES SIMULTANEOUSLY WITH PLANNED FUSION}

Parts D and E had another Flash session, however, this session was potentially the last needed for part E, as it was her last memory. Parts D and E flew on their unicorns and diminished their individual memories. The time came when part E's memory was almost completely desensitized. The bilateral stimulators remained on as they flew on their unicorns. Part W was on the outside with me. I could then see a shift in part W's face, which suggested that something inside had shifted. I asked W if something had changed; she confirmed that part E had fused. She was taken aback and described observing that part E became sleepy then started to "slide off" her unicorn. Then rapidly, part E became a "poof of colors" and "vanished." She knew and felt that part E had fused inside the system.

This example demonstrates that, with use of the Flash technique, two separate memories can be processed simultaneously, and fusion can occur in one part.

\section{PROGRESS TO DATE}

The client is still in ongoing therapy. In 12 months, she had 50 EMDR sessions with around 100 parts fused and a large volume of trauma material processed. She also had approximately 20 Flash sessions, which have been used as a stand-alone tool, without EMDR. The result has been successful, with fusion of 5 more parts and the desensitization of a number of highly disturbing trauma memories.

\section{DISCUSSION}

This paper explores the Flash technique for the treatment of traumatic memory in DID. The Flash technique is a new therapy with a first publication in the last two years, so there is still much to be learned about its use and versatility. I have suggested a number of modifications for use with DID. I described nine variations of the Flash technique, and some of the findings have been quite interesting. The Flash technique can be used for several parts at the same time leading to the complete desensitization of trauma memories and the planned fusion of parts. Strengthening of resources with playful imagination and olfactory stimulation appeared to "boost" the session with increased positive feelings in the body and a faster processing time. Initially the aim was to use Flash therapy and then EMDR, once the memory intensity was tolerable for the parts. However, I found that in many sessions, EMDR did not need to be used at all. 
Manfield and colleagues state, "The Flash technique seems to be most useful for clients who are not highly dissociative" (Manfield et al., 2017, p. 204). In contrast, the work presented in this paper demonstrates its potential use and versatility for even the most poly-fragmented of clients. My client reported feeling comfortable with the therapy; she saw benefits with its use and was happy to undergo further therapy. Manfield et al. (2017) also raised additional questions on the types of bilateral stimulation: "It would be valuable to compare Flash therapy with eye movements, to Flash therapy with bilateral tapping and/or auditory stimulation" (Manfield et al., 2017, p. 204). The work presented here in this paper has demonstrated the successful use of Flash therapy, with bilateral stimulation in the form of handheld bilateral stimulators.

\section{Comparison With EMDR Standard Processing}

I have found that Flash therapy and EMDR both demonstrate a similar ability to desensitize trauma memories. Both techniques can reduce the intensity of trauma memories to the point where the memory is harder to recall, i.e., no remaining images, sounds, tastes, touch or smells, and no remaining somatic sensations or emotions. In the cases discussed, the SUDS often reduced to zero. This is an interesting finding for Flash therapy, which contrasts to the findings in Manfield et al. (2017): "Although Flash therapy appears to reduce the disturbance substantially, it usually does not fully process memories or bring their disturbance down to zero." Flash therapy appears to be significantly faster than EMDR. Flash sessions ranged between five to 45 minutes, whereas EMDR sessions often take between 60 to 90 minutes and may need more than one session for one memory.

\section{Limitations and Further Research}

The Flash technique has demonstrated its effectiveness in complete desensitization of trauma memories with fragmentary young parts, however, it is unlikely that there is complete reprocessing, as is the case with EMDR. With Flash therapy, the therapist does not ask for negative or positive cognitions, however, these are standard elements with EMDR. Thus, one can assume that there is a reduced or lack of cognitive restructuring with Flash therapy. This could be an interesting area to research in the future, whether a cognition component could be added to Flash therapy and what impact this has on the target memory.

I believe there is much further scope for research into use of the Flash technique. One area of importance is in exploring methods to enhance the experience of the engaging activity, thus leading to "boosting" of the therapy and faster processing of the memory. A second area to explore in DID is using the Flash technique to process several different memories at the same time. This should be explored safely, being cautious not to push the 
client further than they can tolerate. In this paper two different memories were successfully desensitized simultaneously; however, I hypothesize that there is potential to process several separate memories at the same time. One could derive massive advantages in reducing therapy time.

\section{CONCLUSION}

This is the second in a series of papers where I have discussed the use of EMDR and the Flash technique in the treatment of traumatic memory, with the resultant fusion of parts in DID. Both therapies have demonstrated their effectiveness in such complex cases. I would like to encourage others working in this field to consider training in these therapies, if they have not done so already. I would very much like to welcome any comments and feedback on the work presented in this paper.

\section{REFERENCES}

Fraser, G. A. (1991). The dissociative table technique: A strategy for working with ego states in dissociative disorders and ego-state therapy. Dissociation, 4(4), 205-213.

International Society for the Study of Trauma and Dissociation. (2011). Guidelines for treating dissociative identity disorder in adults, third revision. Journal of Trauma \& Dissociation, 12(2), 115-187.

Manfield, P., Lovett, J., Engel, L., \& Manfield, D. (2017). Use of the flash technique in EMDR therapy: Four case examples. Journal of EMDR Practice and Research, 11(4), 195-205.

Paulsen, S. (2009). Looking through the eyes of trauma and dissociation: An illustrated guide for EMDR therapists and clients. Charleston, SC: BookSurge Publishing.

Shapiro, F. (1995). Eye movement desensitization and reprocessing: Basic principles, protocols and procedures. New York, NY: Guildford Press.

Shebini, N. (2019). EMDR for Safe Desensitization of Memories and Fusion of Parts in DID. Conference Room Technique, Trauma Mapping and Management of Unplanned Abreactions. Frontiers in the Psychotherapy of Trauma and Dissociation, 3(2), 136-150.

Spiegel, H. (1972). An eye-roll test for hypnotizability. American Journal of Clinical Hypnosis, 15(1), 25-28.

Van der Hart, O., Steele, K., Boon, S., \& Brown, P. (1993). The treatment of traumatic memories: Synthesis, realization, and integration. Dissociation, 6(2-3) 162-180. 